\title{
What else should we know about experiencing COPD? A narrative review in search of patients' psychological burden alleviation
}

This article was published in the following Dove Press journal:

International Journal of COPD

16 September 2016

Number of times this article has been viewed

\section{Marta Rzadkiewicz' \\ Ola Bråtas ${ }^{2}$ \\ Geir Arild Espnes ${ }^{2}$}

'Second Faculty of Medicine with The English Division and The Physiotherapy Division, Department of Medical Psychology, Medical University of Warsaw, Warsaw, Poland; ${ }^{2}$ Center for Health Promotion Research, Norwegian University of Science and Technology, Trondheim, Norway
Correspondence: Marta Rzadkiewicz Department of Medical Psychology, Medical University of Warsaw, Żwirki i Wigury 8I, 02-09I Warsaw, Poland Tel +4822506769634

Fax +48 225720542

Email mrzadkiewicz@wum.edu.pl
Abstract: The present paper is a narrative review focusing on the psychological impact, identification of protective factors, and interventions minimizing the psychological burdens of chronic obstructive pulmonary disease (COPD). The research reviews studies on neurocognitive functions, personality, emotional problems, and health-related quality of life. This is done with regard to resources as well as activities enabling or enhancing a patient's adaptation. PubMed and PsychArticles databases were searched for relevant medical (eg, CODP, emphysema), psychopathology (eg, depression), and psychological (eg, personality) keywords, followed by hand search. After application of the inclusion and exclusion criteria, the search resulted in 82 articles and book chapters. The choice was based on evidence accepted by evidence-based medicine, although at different levels of strength. Psychological experiencing of COPD appears to be very unequally represented with scientific research on emotional problems and functioning decrease significantly outnumbering those addressing resources or effective interventions. As our initial literature search called for an urgent need for further exploration, we have carefully pointed out numerous areas where the knowledge on how to protect or restore psychological well-being among COPD patients should be broadened.

Keywords: COPD, chronic illness, psychological intervention, personality, mental health, HRQoL

\section{Introduction}

In 2012, chronic obstructive pulmonary disease (COPD) was identified as responsible for $6 \%$ of the global deaths, ${ }^{1}$ and together with other chronic respiratory diseases, the third leading cause of death from noncommunicable diseases. ${ }^{2}$ The main symptoms patients experience are chronic cough, extensive sputum production, and dyspnea. Tobacco use and physical inactivity are seen as major risk factors for this illness and found to be worsening the existing disease. COPD progresses through gradual and irreversible airflow limitation. ${ }^{3}$ Mortality rates increase with disease severity, especially after exacerbations that require hospitalization. ${ }^{4}$ Nonetheless, in clinical practice the necessity of psychological help for COPD patients appears less obvious than for example in cardiology or oncology. ${ }^{5,6}$ This calls for action to identify psychological resources and interventions which neutralize the negative impact of the disease on patients' functioning. The present study recognizes psychological burdens which a patient diagnosed with COPD may experience, yet also searches for factors that, despite progressing illness, protect, stabilize, or improve mental health, quality of life (QoL), and well-being - no matter if this means individual dispositional trait or interventions provided from the outside. 
Among the patients with COPD, various psychological aspects of functioning have been investigated but so far with little consequence for clinical practice and an almost total neglect in the treatment guidelines. ${ }^{3,4}$ For example, in the Global initiative for chronic Obstructive Lung Disease guideline, the term psychol* appeared only three times and exclusively in references, "psychotherapy" is not even mentioned, whereas "depression" was found 23 times. $^{4}$ At the same time, the range of psychological issues extends from neuropsychological deficits, ${ }^{7}$ through disorders, such as anxiety or depression, ${ }^{8}$ to a substantial decrease in QoL. ${ }^{9}$ It is of major importance that all these psychological strains may reflect badly on general health condition, comprising exacerbations, hospitalizations, symptoms, rehabilitation, adherence, and survival. ${ }^{10,11}$ Finally, the psychological experience of living with COPD is closely related to the patient's general well-being, daily activities, physical activity, social role engagement, and caregivers' burden. ${ }^{12,13}$ Despite the listed problems, research exploring psychological resources buffering the burden imposed by the illness is still less represented than in other chronic conditions. In the present article, studies both recognizing the hardships endangering patients' psychological condition and programs found to be beneficial to their neuropsychological functioning, personality, emotional state, and QoL are described. Issues mentioned earlier are scattered on an extensive area of scientific interest, leaving genuine theoretical and methodological disparities (eg. techniques to analyze brain tissue damage). For this reason systematic comparisons might emerge impractical. Therefore, to allow comprehensive integration of the area, yet covering important subtleties, a narrative review was considered to be the most relevant. ${ }^{14,15}$ This approach permits some flexibility in pointing to areas for further exploration. ${ }^{16}$

\section{Methods}

\section{Search strategy}

The MEDLINE database was searched using PubMed engine along with PsychArticles database. The following strings of key words were joined to search titles/abstracts via PubMed:

- COPD or Chronic Obstructive Pulmonary Disease or chronic airway obstruction or chronic bronchitis or emphysema and

- psychological or cognitive or personality or emotional or coping or quality of life or adaptation to illness or adjustment to illness or behavioral and

- psychopathology or mental health or psychiatric or depression or anxiety or PTSD or intervention.
The search yield 183 articles from PubMed and 21 from PsychArticles (in latter case only the first stream of given keywords was used). Inclusion criteria were the diagnosis of COPD (from medical records, dedicated screening, or self-reported by the patient) and at least one psychological factor with a clearly indicated assessment. After exclusion of duplicates, the papers describing problems rooted elsewhere than in COPD, those with samples limited to persons caring for COPD patients, COPD samples that are not adequate for generalization (eg, only females during menopausal period), or small sample sizes that were included in earlier reviews consisted of 71 papers. Hand search of the reference lists along with personal and college libraries searching added eleven articles and chapters to the review. Both primary research and reviews were included. The search resulted in 82 studies to be analyzed. After a narrative synthesis, four main areas of our focus were established: neurocognitive, personality, emotional problems, and QoL.

\section{Quality of the researched studies}

High-quality studies were analyzed when available (we included six systematic reviews with meta-analysis and five randomized controlled trials), with complementing knowledge from moderate strength of evidence (mostly controlled case-series, cohort, or follow-up and cross-sectional studies). Wherever an issue is covered only by lower levels of evidence, our relevant comment appears. Commune limitations of the analyzed studies are small sample size, lack of control group, and an inconsistency between the studies' outputs.

\section{Discussion Neuropsychological aspects}

The general intellectual level is in large reported normal in patients with COPD $;{ }^{17}$ nevertheless, in various mental tasks, subtle cerebral declines are systematically shown. ${ }^{18}$ The prevalence of neuropsychological disturbances falls within a wide range from $0 \%{ }^{19}$ to $88 \%{ }^{20}$ of patients, depending on the study ${ }^{21}$ Noteworthy, in the majority of research, the cognitive deficit itself is not implicitly defined. ${ }^{7}$ This limits its value as evidence and makes any comparisons very difficult.

Neurocognitive impairment is mostly attributed to the reduced oxygenation of the brain tissue due to hypoxia, ischemia, or hypercapnia. ${ }^{22,23}$ This mental deterioration is identified mainly in the areas of memory and learning, motor skills, attention, abstractive thinking, plasticity, alertness, problem solving, and speed of information processing. . $21,22,24,25$ One of the most popular tools evaluating cognitive capacity is the Mini Mental State Examination, frequently used in COPD 
patients as well. ${ }^{19,22,26}$ Despite some deficits found even with this methodology, the test is perceived as insufficiently sensitive to reveal subtle, but important impairments related to the course of COPD. ${ }^{7}$ This example of methodological shortcomings illustrates and explains discrepancies in the research showing changes below or above clinical significance. Other tests used diagnose single, and thus difficult to compare between studies, cognitive abilities, or are incorporated in large batteries, difficult to apply among patients who are elderly and/or have advanced stages of COPD.

Lower scoring in the neuropsychological tests may also be partially explained by the age and education of the COPD patients, where the majority are elderly (60+) and often less educated than their peers, as this illness most often affects the lower social classes..$^{27-29}$ Nevertheless, these factors are unlike to constitute the sole reasons for mental deterioration, as the research standards nowadays require age- and education-matched control groups.

Patients during exacerbation or with more advanced disease stage have more cognitive deficits, and thus pulmonary functions and current medical condition can be seen as another important factor. ${ }^{7,30}$ This effect may, however, relate to worse general physiological and/or psychological functioning, such as when suffering from comorbidities. ${ }^{28,31}$ Some results show also that non-hypoxemic COPD patients display neuropsychological deficits, particularly in the routine cognitive tasks, processing speed, and cognitive plasticity. ${ }^{32,33}$ Moreover, lung functions and blood gases were not found to have any predictive value for the estimation of the neurocognitive functions, especially in mild to moderate COPD, ${ }^{7,33,34}$ again with some exceptions. ${ }^{35}$ Hypoxemia, when isolated, does not directly induce neuronal damage, provided that it is not accompanied by reduced cerebral blood flow. ${ }^{36,37}$ Cerebral blood-flow is usually not controlled during cognitive tasks. Since this factor might explain discrepancies between the studies' outputs, it should be taken into consideration in future research. Although cognitive changes can be difficult to diagnose in clinical practice or even to one's individual notice, its possible influence on daily functioning should be monitored. A recent large study shows that $25 \%$ of patients reporting diagnosed COPD perceive memory deficits and related confusion, with the prevalence of functional limitations within this group that is higher than in general population. ${ }^{38}$

Studies based on magnetic resonance imaging (MRI) scans have shed more light on this unclear picture of the neuropsychological changes. Although the patients' cognitive performance is disturbed, it has been previously shown that the general brain structure stays unchanged or that the registered pathology is dispersed. ${ }^{35,39}$ However, analysis with voxelbased morphometry revealed locally the gray matter volume reductions in COPD group in comparison with the scans of the control participants. ${ }^{40}$ Furthermore, and interestingly, the changes were related to COPD duration, blood $\mathrm{PO}_{2}$ values, and neuropsychological measurement. Supporting data show that gray matter volume reductions are related to a fear of dyspnea and fear of physical activity, possibly worsening the course of disease on behavioral background. ${ }^{41}$ Both the aforementioned articles report decreases in gray matter volume within the posterior and anterior cingulated cortex, midcingulate cortex, hippocampus, and amygdala - regions related to processing both dyspnea and fear-but the absence of generalized cortical degeneration. Additionally, no damage on microscopic level was found in brain tissue of deceased subjects with COPD. ${ }^{42}$

Van Dijk et al, ${ }^{43}$ examining a large patient sample, revealed that periventricular white matter changes might also be partly responsible for the cognitive decline by being related to decreased arterial oxygen saturation and COPD presence. Moreover, a greater risk of white matter damage was noticed for patients with higher levels of oxygen desaturation during, even mild, physical activity. ${ }^{39}$ It is noteworthy that, despite smoking being a leading risk factor for COPD, the links between smoking or pack-years and neuropsychological performance still remain unconfirmed in this group of patients. ${ }^{34,35}$

Even though the neuropsychological burden of COPD may often be reported to be below what is considered of clinical significance, a strong argument for paying close attention to cognitive functions is given by Shipley et al. ${ }^{44}$ Their prospective analyses prove, particularly for the $60+$ population, that impaired cognitive functions (slower and more variable reaction times and poorer tests performance) are associated with higher risk of premature death in patients with respiratory diseases. For COPD, this result was confirmed when neuropsychological tests in drawing, visual perception and memory, and processing speed were independent predictors of mortality during 32- to 36-month follow-up. ${ }^{17,45}$ However, these findings need to be tested in larger samples with a focus on processes leading to the mentioned relationship.

Summarizing, there is an agreement about association between neurocognitive deficits and the disease in COPD patients, but the role of pulmonary functions and blood gases is yet to be finally established. Changes in gray and white brain matters are shown; however, the mechanisms underlying the cognitive impairments remain unexplained. In future studies, it is crucial that more attention is paid to the impact 
of cognitive decline resulting from COPD on everyday life, health, and self-care abilities, as the data concerning these issues are very limited. Of great importance is also an identification of resources protecting from debilitating influence of the progressing illness on mental efficiency, as to our knowledge there is no available research in this area.

\section{Interventions to improve neurocognitive functioning}

There are few psychological intervention studies of COPD patients that control for neuropsychological functioning and none giving strong evidence. Providing supplemental longterm oxygen therapy cannot fully eliminate existing cognitive differences between COPD patients and their healthy peers; nevertheless, partial improvement is possible. ${ }^{24}$ There is a suggestion from Borson et $\mathrm{al}^{39}$ to provide intervention with oxygen therapy for patients who suffer from desaturation when physically active. Addressing dyspnea and illnessrelated fears is recently hypothesized to have restraining or even reverse effect on gray matter volume reductions, thus improving mental functions. ${ }^{41}$ Still, further clinical studies are obliged to test both possibilities, as the conclusions and proposed solutions come from isolated research results.

Pulmonary rehabilitation and physical exercises are considered as the most influential interventions regarding mental functioning, ${ }^{28,46,47}$ likely due to increased blood circulation and oxygenation, permitting better performance in the brain cells. For example, a 3-week-long program of physical activities resulted in a significant improvement of visual attention and semantic fluency. ${ }^{47}$ There are studies, however, suggesting that any increase in cognitive functioning, which is associated with physical exercise, is not lasting unless the exercise routine is continuously maintained. ${ }^{48}$

Dodd et $\mathrm{al}^{22}$ proposed in their review a complex and quite radical model to help patients with COPD. The intervention should include lung volume reduction surgery, pulmonary rehabilitation, treating comorbidities, cognitive training, oxygenation, and ventilation. Cognitive improvement achieved this way is assumed to result in positive changes in the areas of: medication adherence, length of hospital stay, mortality, discharge destination, activities of daily living, and health status. Although there are studies supporting much of predicted connections, others remain sparsely explored or not confirmed. To our knowledge, only one modern study provided cognitive training to COPD patients, reporting no influence on neuropsychological tests performance after 6 months. ${ }^{49}$ As the sample was small and heterogeneous, this statement needs to be further researched. Other psychological interventions, such as neuropsychological rehabilitation, to alleviate cognitive burden have not been researched yet.

\section{Personality and related psychological characteristics}

Personality is psychologically described in many different ways and measured with a variety of tools, from those enclosing all main features to others analyzing a particular trait. ${ }^{50}$ The working assumption for this review is that, whatever the way of assessing personality, the main aim when describing it is to picture the stable dispositions an individual has for feeling and behaving.

Personality has seldom been analyzed in COPD patients. Moreover, available studies are diverse in terms of theoretical concepts, samples, and methodology, and only few of them appear to concentrate on the same or similar personality dimensions. Available literature depicts rather biased and incomplete portrait of general personality when suffering from COPD. The bias comes mostly from using Minnesota Multiphasic Personality Inventory (a popular measure in psycho-medical research) or other tools, which reflect psychopathology rather than a well-defined personality. ${ }^{21,51}$ On the basis of these data, COPD patients have elevated scores on dimensions, such as hypochondria, depression, hysteria, psychastenia, inhibition, introversion and sensitiveness, despair, and hostility. Searching for resources in this group, we found only extraversion, being shown as a protective factor in deaths from respiratory diseases in general population. ${ }^{52}$ Additionally, respectful (scrupulous and collaborative) style of functioning which was identified among COPD patients ${ }^{51}$ might play a role in compliance, as it is known in other chronic illnesses. The last study, however, is limited by a small and specific sample and thus should be interpreted with care. An urgent need arises from a lack of positive research on the general personality to study now its potential role as a resource enhancing patients' adaptation to COPD. As the disease is progressive, prospective studies might bring an additional knowledge on vulnerable and stable features of personality when facing COPD, enabling development of more effective interventions.

The discrete personality components are probably better documented in COPD population, with self-esteem and coping abilities receiving the strongest focus. Self-efficacy was found in this group lower than average and related to the level of illness acceptance (understood as psychological adaptation), ${ }^{53}$ social support, number of perceived negative consequences of the illness, and understanding of current health condition. ${ }^{54}$ Higher self-efficacy was also shown as: a mediator between biomedical factors and better QoL, ${ }^{55}$ 
a protector from exacerbations, ${ }^{53}$ and a correlate of higher self-reported adherence. ${ }^{56}$

The style of coping with stressful events is closely related with personality and was also examined in COPD patients, but gives inconclusive results. Problem- and emotion-focused styles, along with low self-rated health and older age, predicted worse adaptation to COPD, whereas the general measurement of coping stayed unrelated. ${ }^{57}$ To our knowledge, there is no research confirming emotion-focused coping style links with lower compliance, more frequent exacerbations, or hospitalizations in COPD, as it was revealed among patients with asthma. ${ }^{58}$ When defensive mechanisms were analyzed as coping strategies, rather immature and neurotic style is assigned to COPD patients, which is related to lower health-related quality of life (HRQoL). ${ }^{59}$ In another study, catastrophic strategies of coping and low self-efficacy both correlated not only with lower QoL, but also with depression and anxiety. ${ }^{60}$

Summarizing the existing understanding of the general and more subtle personality traits, rather surprisingly, seems less reliable than the one of psychiatric comorbidity in COPD (which is described in the following), although the former may buffer or be a risk factor for the latter. The relationship of COPD progress, lung functions, or exacerbations with personality is also unknown. Extraversion, conscientiousness, locus of control, and self-esteem are just a few examples of issues still to be explored; therefore, a comprehensive assessment of personality in this group of patients calls for prompt research. Additionally, often reliant on personality are: locus of health control, coping with illness, acceptance, attitude toward it, and so on. ${ }^{13,61}$ All of them are known to be important resources in psycho-medical investigations and should be appreciated among COPD patients, at least at the level comparable with other leading chronic conditions. . $^{13,62,63}$

\section{Interventions and personality}

Despite personality being perceived as a stable psychological construct, once developmental processes have ended, some researchers successfully analyzed improvement of its traits along the intervention programs for COPD patients. Interventions based on behavioral medicine indicate general selfefficacy as a main mediating factor between self-management education and improvements of clinical outcomes. ${ }^{64}$ More specific dyspnea self-management program delivered via internet, biofeedback, or participating in sessions of group singing (seen as a breathing control training joint with social support) are described as having a beneficial effect on selfefficacy. ${ }^{64}$ However, before they can be recommended in clinical practice, these positive results still need to be confirmed in large and well-controlled studies.

More robust relationship is shaped between self-efficacy and pulmonary rehabilitation, where physical activity enhances self-efficacy and vice versa. In a small study by Güell et al, ${ }^{51}$ pulmonary rehabilitation also improved other personality dimensions (although described in terms of pathology), such as hostility, introversion, sensitivity (negativistic style), or forcefulness. Blumenthal et $\mathrm{al}^{12}$ found improvements in coping skills measured through active coping, disengagement, and support seeking after telehealth coping skills intervention (TCSI). No interventions dedicated to enhance general personality or its main components were found for patients with COPD.

\section{Emotional problems and psychopathology}

In a large sample of patients self-reporting COPD, 77\% had an unimpaired psychological well-being. ${ }^{27}$ Nonetheless, this group of patients more often than general population declares frequent mental distress. ${ }^{38}$ Constraints of the airflow in general can cause emotional challenges, mainly from the anxiety-depression spectrum, and usually mild to severe disturbances are noted. ${ }^{8,10}$ Most common problems include preclinical and psychiatric issues defined as fears, worries, low mood, apathy, lack of energy, depression, anxiety, panic attacks, and less often psychosis. ${ }^{65-67}$ Moreover, acute COPD exacerbation is experienced as traumatic ${ }^{68}$ and symptoms from posttraumatic stress disorder (PTSD) spectrum were observed after a stay at the intensive care unit. ${ }^{5}$ Hospitalization for COPD exacerbation might additionally trigger aggression ${ }^{68}$ whereas anxiety and depression rates rise when PTSD symptoms are present., ${ }^{5,69}$ Noteworthy, anxiety and depression belong to leading comorbidities in $\mathrm{COPD}^{4,8,9}$ and symptoms of both are often overlapping, ${ }^{70}$ giving a tangled picture of functional disturbances.

\section{Anxiety}

Anxiety symptoms in COPD population comprise panic disorder, panic attack, general anxiety disorder, and PTSD assessed through Diagnostic and Statistical Manual of Mental Disorders - IV, International Classification of Diseases - 10th edition criteria, or by means of adequate questionnaires. ${ }^{21}$ In a multicenter study, symptoms of PTSD were noted in $20.7 \%$ of patients at 90 days postdischarge after intensive care unit admission for exacerbation. ${ }^{5}$ At discharge, recollections of suffocation, pain, and sleep disturbance were prevailing most often. Feeling of imminent death was experienced by nearly $40 \%$ and nightmares by $50 \%$ of the patients, whereas 
some $20 \%$ reported recalls, such as abuse, betrayal, hallucinations, and abandonment. A recent study showed that the occurrence of two or more COPD exacerbations in the previous year led to a near twofold increase in PTSD ratio, ${ }^{69}$ confirming a strong relation between health condition and this psychological disorder.

The appearance of anxiety symptoms derives probably from interrelations between breathlessness and anxiety. The most obvious seems a vicious circle between breathlessness and fear, of a sudden death in particular. Hence, a 50\% prevalence of panic attacks in COPD patients is understandable. ${ }^{67}$ On average, COPD patients seem to report symptoms of anxiety at least twice as often as healthy controls (13\% vs $6 \%{ }^{71}$ or $10 \%$ vs $3.3 \%{ }^{72}$ ) and more often than patients with heart disease, cancer, and other diagnosis. ${ }^{73}$ However, the exact prevalence is difficult to determine on the basis of existing literature as it falls in the broad range between $10 \%$ and $96 \%$. The reported rates are lower for clinical assessment than for self-report measures. ${ }^{65}$ The influence of anxiety on the course of disease and everyday functioning generally goes via QoL, yet is not fully understood. On one hand, higher anxiety appears to be linked with choosing to participate in rehabilitation ${ }^{74}$ but not with low physical activity ${ }^{75}$ on the other hand, also to nonadherence to medical treatment. ${ }^{56}$

\section{Depression}

The International Classification of Diseases - 10th edition and Diagnostic and Statistical Manual of Mental Disorders IV - based interview methods, together with questionnaires, are often used to assess depressive symptoms in COPD patients. This emotional disturbance was reported in $7 \%$ up to $79 \%$ of patients, ${ }^{21}$ with a narrower range $(16 \%-47 \%)$ for clinical assessment. ${ }^{65}$ For various reasons, COPD may be seen as a cause of emotional burden, but depression has just as much impact on patients' health itself and thus is associated with poor prognosis. It should be emphasized that, although high prevalence of depressive symptoms in COPD is recognized in epidemiology, the diagnosis and especially treatment of it are usually disregarded in clinical practice. 5,6,76 This appears surprising in the light of a number of studies which show that for this group of patients, comorbid depression has a real influence on medical condition's indicators, such as hospitalizations, exacerbations, more disturbing symptoms, and eventually raised rates of mortality. Within the dimension of lifestyle, depression is linked with persistent smoking, social withdrawal, lower physical activity, lower medical compliance, and impaired QoL in general, as well as HRQoL. ${ }^{11,56,77}$ Such an extensive body of evidence urges the actions to diagnose patients' emotional status in detail on everyday practice to keep their psychological health intact or restore, if needed.

Less than half of anxious or depressive COPD patients are diagnosed and less than a third of them receive appropriate treatment. ${ }^{76}$ The risks of anxiety and depression are increased in younger patients, ${ }^{67}$ females, smokers, and those living alone, having recent exacerbation, lower first second forced expiratory volume $\left(\mathrm{FEV}_{1}\right)$, cardiovascular disease history, ${ }^{4,11,78}$ suffering from dyspnea, shortness of breath, or fatigue. ${ }^{10} \mathrm{~A}$ recent, population-based study compliments this list with risks of anxiety disorder, such as depression, pain and disability, insomnia, low socioeconomic status, and social isolation. ${ }^{79}$ There is no clear evidence that the stage of the disease ${ }^{39}$ or the pulmonary functions ${ }^{34}$ mediate severity of the emotional problems. Again, the very important information about what is buffering against emotional decline is still to be established.

\section{Intervention and emotional problems}

Alleviation of emotional burden gets increasing interest in research with recent focus on comprehensive methods (for reviews see Baraniak and Sheffield, ${ }^{80}$ Coventry et al, ${ }^{81}$ and Fritzsche et $\mathrm{al}^{82}$ ). However, a limited small number of high quality studies in this area is pointed out by the reviewers. ${ }^{81,83}$ Lack of clear criteria of emotional problems and its change implies cautious interpretation. There is a possibility that the same program may have a positive influence on the reduction of self-reported symptoms, but have no effect on clinical condition. Simultaneously, psychological interventions have been found to be more beneficial to patients suffering from anxiety than those with depression. ${ }^{80}$

A psychological approach that seems particularly promising is cognitive behavioral therapy (CBT) ${ }^{84}$ Its facets of specific techniques allow COPD patients to break vicious cycles of dyspnea-fear or dyspnea-reduced activity, as well as identifying cognitive distortions of one's physical capabilities along with their emotional costs. ${ }^{8}$ Although one randomized controlled trial study shows that CBT group therapy is comparable with a similar amount of time of education given to the patients, ${ }^{85}$ the coping skills training, mentioned earlier and also rooted in CBT, recently surpassed the effect of education. ${ }^{12}$ The authors show that 16 -week long TCSI improved not only emotional functioning but also general QoL and somatic dimension of QoL index. Noteworthy, COPD patients who entered the trial with higher levels of emotional problems benefitted from TCSI even more than those with subclinical results at baseline did.

Valenza et $\mathrm{al}^{86}$ found that teaching patients hospitalized for exacerbation the techniques of controlled breathing can 
be efficient in reducing anxiety and depression. Additionally, a modifying effect on the panic attacks appearance was identified when patients' specific illness perceptions were analyzed ${ }^{67}$ The main limitation of the aforementioned studies is however the measurement with no follow-up and having a small sample size. Larger research to confirm the earlier effects is required before interventions might be applied. Then, emphasizing additional mental control of breathing might appear important in psychological interventions, not only to treat existing burden in COPD patients but for example also to prevent PTSD symptoms among those with exacerbations. Less studied techniques, including problem solving, social support enhancement, biofeedback, attention distraction when exercising, laughter and sense of humor, or relaxation are also drawing scientific interest, but to a lesser extent. ${ }^{64,81}$

Among the nonpsychological therapies, pulmonary rehabilitation appears as a good mood stabilizer, but long-term maintenance of its positive effect is still questionable. . $^{87,88}$ Searching through psychological and lifestyle interventions in one systematic review, the strongest effects were observed with composed programs, which included physical exercises. ${ }^{81}$ The impact was independent of the severity of anxiety or depression. Lifestyle treatments comprised facilitated discussions, illness-specific exercises, education, skills and self-management training, behavior therapy, or relapse prevention.

Participation in pharmacotherapy for comorbid depression and/or anxiety in COPD is known as having high rates of refusal. The problem of noncompliance is mainly due to patients' misconception of the treatment, feeling stigmatized, not accepting the diagnosis or being discouraged by side effects. Existing data about treatment effectiveness are limited and inconclusive because of small sample sizes, different measurements of symptoms, and treatment outcomes (reviews ${ }^{8,89}$ ). Although the Global initiative for chronic Obstructive Lung Disease guidelines list both conditions as major comorbidities, nonpharmacological treatment was not proposed in this standard. ${ }^{4}$

\section{Quality of life}

Acknowledging all the mentioned burdens, impaired QoL in people suffering from COPD seems natural, but what is of great importance, it is lower than in other chronic conditions and still decreases with illness progression. ${ }^{90}$ Nevertheless, the knowledge about the influence of COPD on QoL seems insufficient for most of the research focuses on the concomitant presence of emotional problems or other conditions. For example, QoL in COPD patients is usually significantly related to anxiety and depression., ${ }^{9,11,66,77,91}$ Among patients with cystic fibrosis, both were related not only to all subscales and the general outcome of QoL measurement but also to the limitation of physical activity and lower lung function..$^{92}$ Even within couples, the spouse's anxiety may explain the variance in the patient's QoL. ${ }^{65}$ Interestingly, Cully et al ${ }^{66}$ revealed that the mental health component of QoL was linked to both anxiety and depression, whereas the physical health element of QoL was associated only with the anxiety level. Nevertheless, a prospective explanation whether decrease in QoL leads to psychological comorbidity or vice versa seems still difficult. The tight bonds were also exposed by Hoth et $\mathrm{a}^{93}$ when patients (with a significant smoking history) attributing falling ill to a general psychological factor was related to a lower QoL along with increased depression and anxiety. Thus, ruminating about responsibility for illness is probably maladaptive, but further studies are required to confirm this conclusion. Supporting this hypothesis, illness perceptions when adequate, and therefore more adaptive, were found to be associated with better HRQoL, whereas this relation was not confirmed for proactive coping. ${ }^{9}$

COPD has been shown to cause greater impairment on HRQoL in females. ${ }^{29,94}$ But, regardless of sex, worsening of HRQoL was found to be related to a decrease in $\mathrm{FEV}_{1}$, partial pressure of oxygen in arterial blood $\left(\mathrm{PaO}_{2}\right)$, elevated dyspnea, and previous exacerbations. ${ }^{77}$ On the contrary, selfreported physical activity, exercise, social support, economic safety, and teetotalism were identified as resources helping to maintain HRQoL and interpreted as having a buffering effect for COPD patients. ${ }^{27}$ Possibilities of enhancement in the mentioned areas can become a very valuable source of evidencebased interventions to improve patients' HRQoL, especially when these resources remain significant at all stages of the disease. Prospective studies examining positive determinants for a better HRQoL in COPD are still required.

\section{Improving QoL through intervention}

Improved QoL, especially HRQoL, is the most common patient-reported effect of pulmonary rehabilitation. ${ }^{95}$ The literature repeatedly announces beneficial, but short-term, consequences of rehabilitation programs; the shorter the physical activity cycle, the shorter its positive influence on HRQoL/QoL. ${ }^{87}$ The severity of COPD may play an additional role in predicting the beneficial effect of rehabilitation on HRQoL, with mild to moderate stages being more promising. ${ }^{74}$ The HRQoL improvement may also be mediated through self-effectiveness increasing with exercise tolerance ${ }^{96}$ or decrease in depressive symptoms observed after rehabilitation. ${ }^{74,8687}$ Studies establishing optimal conditions, 
methods, duration, and intensity of training are still needed to construct appropriate standards.

Promising QoL improvements were found through TCSI delivered via telephone calls. ${ }^{12}$ Participants were found to improve in various aspects of psychological QoL - vitality, social and emotional role functioning, perceived social support, and better overall mental health. Moreover, the patients reported higher somatic indicators of QoL: less fatigue and shortness of breath and increased functional capacity and physical activity. Apart from exercise or rehabilitation and CBT, self-management programs, biofeedback training, sense of humor, and singing classes were also found beneficial for QoL in COPD patients but with a low level of evidence due to small samples and isolated research. ${ }^{64}$

\section{Conclusion}

Summarizing the review, it may be concluded that research devoted to understanding the disturbances and psychopathology in COPD seems to outnumber studies focusing on more protective or stabilizing factors. The latter, especially when early assessed and enhanced, might act as natural resources, crucial in buffering described psychological burden from appearance. Although large discrepancies between the studies make exact estimation of prevalence impossible, high rates of emotional problems, decreased QoL, and cognitive changes are confirmed. Especially, emotional problems and QoL impairment seem alarming for being more common and/or having higher levels than in other chronic conditions, at the same time being less studied toward its prevention. For example, very little is known about the role of personality and related psychological dimensions in improving resilience when having COPD.

Among various interventions, cognitive behavioral approach composed with nonpsychological forms, for example, including physical activity, breathing control, or addressing comorbidities, seem most promising. The efficacy of neuropsychological rehabilitation or support groups along with other interventions are the areas yet to be researched. Further studies with well-defined psychological background, and larger and longitudinally followed samples are urgently needed to enable evidence-based interventions to be planned and applied. They should be focused on enhancement of adjustment to illness, preserving mental health, and QoL.

\section{Author contributions}

All authors contributed to the article conception/design, literature search, drafting, and writing manuscript.

\section{Disclosure}

The authors report no conflicts of interest in this work.

\section{References}

1. WHO (2015). COPD Fact Sheet. Available from: http://www.who.int/ mediacentre/factsheets/fs315/en/, http://www.who.int/respiratory/copd/ en/. Accessed February 16, 2016.

2. WHO (2014). Global Status Report on Noncommunicable Diseases. Available from: http://apps.who.int/iris/bitstream/10665/148114/1/ 9789241564854_eng.pdf. Accessed February 16, 2016.

3. Decramer M, Janssens W, Miravitlles M. Chronic obstructive pulmonary disease. Lancet. 2012;379(9823):1341-1351.

4. GOLD. In global strategy for the diagnosis, management and prevention of COPD, Global Initiative for Chronic Obstructive Lung Disease (GOLD); 2015. Available from: http://www.goldcopd.org/. Accessed December 18, 2015

5. Miranda de S, Pochard F, Chaize M, et al. Postintensive care unit psychological burden in patients with chronic obstructive pulmonary disease and informal caregivers. A multicenter study. Crit Care Med.2011; 39(1):112-118.

6. Kim HF, Kunik ME, Molinari VA, et al. Functional impairment in COPD patients: the impact of anxiety and depression. Psychosomatics. 2000;41(6):465-471.

7. Schou L, Østergaard B, Rasmussen LS, Rydahl-Hansen S, Phanareth K. Cognitive dysfunction in patients with chronic obstructive pulmonary disease - a systematic review. Respir Med. 2012;106(8):1071-1081.

8. Pumar MI, Gray CR, Walsh JR, Yang IA, Rolls TA, Ward DL. Anxiety and depression - important psychological comorbidities of COPD. J Thorac Dis. 2014;6(11):1615-1631.

9. Waldam SWM, Lammers J-WJ, Decates R, Schuurmans MJ. Daily activities and health-related quality of life in patients with chronic obstructive pulmonary disease: psychological determinants: a crosssectional study. Health Qual Life Outcomes. 2013;11:190. Available from: http://www.hqlo.com/content/11/1/190.

10. Doyle C, Palmer S, Johnson J, et al. Association of anxiety and depression with pulmonary-specific symptoms in chronic obstructive pulmonary disease. Int J Psychiatry Med. 2013;45(2):189-202.

11. Ng T-P, Niti M, Tan W-C, Cao Z, Ong K-C, Eng P. Depressive symptoms and chronic obstructive pulmonary disease. Effect on mortality, hospital readmission, symptom burden, functional status, and quality of life. Arch Intern Med. 2007;167(1):60-67.

12. Blumenthal JA, Emery CF, Smith PJ, et al. The effects of a telehealth coping skills intervention on outcomes in chronic obstructive pulmonary disease: primary results from the INSPIRE-II study. Psychosom Med. 2014;76(8):581-592.

13. Scharloo M, Kaptein AA, Weigman J, et al. Illness perceptions, coping and functioning in patients with rheumatoid arthritis, chronic obstructive pulmonary disease and psoriasis. J Psychosom Res. 1998;44(5):573-585.

14. Collins JA, Fauser BC. Balancing the strengths of systematic and narrative reviews. Hum Reprod Update. 2005;11(2):103-104.

15. Green BN, Johnsons CD, Adams A. Writing narrative literature reviews for peer-reviewed journals: secrets of the trade. J Chiropr Med. 2006; 5(3):102-117.

16. Baumeister RF, Leary MR. Writing narrative literature reviews. Rev Gen Psychol. 1997;1(3):311-320.

17. Fix AJ, Daughton D, Kass I, Bell CW, Golden CJ. Cognitive functioning and survival among patients with chronic obstructive pulmonary disease. Int J Neurosci. 1985;27(1-2):13-17.

18. Rzadkiewicz M. Zmiany neuropsychologiczne w wybranych schorzeniach układu oddechowego. [Neuropsychological changes in selected respiratory diseases]. In: Jodzio K, Nyka WM, editors. Neuropsychologia Medyczna - Wybrane Zagadnienia [Medical NeuropsychologySelected issues]. Gdańsk: Arche; 2008:67-88. Polish.

19. Isoaho R, Puolijoki H, Huhti E, Laippala P, Kivel. Chronic obstructive pulmonary disease and cognitive impairment in the elderly. Int Psychogeriatr. 1996;8(1):113-125. 
20. Kass I, Dyksterhuis JE, Rubin H, Patil KD. Correlation of psychophysiologic variables with vocational rehabilitation outcome in patients with chronic obstructive pulmonary disease. Chest. 1975;67(4):433-440.

21. Hynninen KMJ, Breitve MH, Wiborg AB, Pallesen S, Nordhus IH. Psychological characteristics of patients with chronic obstructive pulmonary disease: a review. J Psychosom Res. 2005;59:429-443.

22. Dodd JW, Getov SV, Jones PW. Cognitive function in COPD. Eur Respir J. 2010;36(1):913-922.

23. Incalzi RA, Gemma A, Marra C, Muzzolon R, Capparella O, Carbonin P. Chronic obstructive pulmonary disease. An original model of cognitive decline. Am Rev Respir Dis. 1993;148(2):418-424.

24. Borak J, Śliwiński PB, Tobiasz M, Górecka D, Zieliński J. Psychological status of COPD patients before and after one year of long-term oxygen therapy. Monaldi Arch Chest Dis. 1996;51(1):7-11.

25. Grant I, Heaton RK, McSweeney AJ, Adams KM, Timms RM. Neuropsychologic findings in hypoxemic chronic obstructive pulmonary disease. Arch Intern Med. 1982;142(8):1470-1476.

26. Incalzi RA, Chappini F, Fuso L, Torrice MP, Gemma A, Pistelli R. Predicting cognitive decline in patients with hypoxaemic COPD. Respir Med. 1998;92(3):527-533.

27. Arne F, Lundin F, Boman G, Janson S, Janson C, Emtner M. Factors associated with good self-rated health and quality of life in subjects with self-reported COPD. Int J Chron Obstruct Pulmon Dis. 2011;6 511-519.

28. Etnier J, Johnston R, Dagenbach D, Pollard RJ, Rejeski WJ, Berty M. The relationships among pulmonary function, aerobic fitness, and cognitive functioning in older COPD patients. Chest. 1999;116(4): 953-960.

29. Kanervisto M, Saarelainen S, Vasankari T, et al. COPD, chronic bronchitis and capacity for day-to-day activities: negative impact of illness on the health-related quality of life. Chronic Respir Dis. 2010; 7(4):207-215.

30. Grant I, Prigatano GP, Heaton RK, McSweeney AJ, Wright EC, Adams KM. Progressive neuropsychologic impairment and hypoxemia. Relationship in chronic obstructive pulmonary disease. Arch Gen Psychiatry. 1987;44(11):999-1006.

31. Kaptein AA, Scharloo M, Fischer MJ, et al. 50 years of psychological research on patients with COPD - road to ruin or highway to heaven? Respir Med. 2009;103(1):3-11.

32. Prigatano GP, Wright EC, Levin D. Quality of life and its predictors in patients with mild hypoxemia and chronic obstructive pulmonary disease. Arch Intern Med. 1984;144(8):1613-1619.

33. Liesker JJW, Postma D, Beukema RJ, et al. Cognitive performance in patients with COPD. Respir Med. 2004;98(4):351-356.

34. Rzadkiewicz M. Przystosowanie do przewlektej choroby somatycznej $u$ pacjentów z oraz bez uszkodzeń mózgu [Adjustment to chronic somatic disease among patients with or without brain damage - dissertation]. Warsaw: University of Warsaw; 2006. Polish.

35. Liao D, Higgins M, Bryan NR, et al. Lower pulmonary function and cerebral subclinical abnormalities detected by MRI. Chest. 1999; 116(1):150-156.

36. Pearigen P, Gwinn R, Simon RP. The effects in vivo of hypoxia on brain injury. Brain Res. 1996;725(2):184-191.

37. Simon RP. Hypoxia versus ischemia. Neurology. 1999;52:7-8.

38. Greenlund KJ, Liu Y, Deokar AJ, Wheaton AG, Croft JB. Association of chronic obstructive pulmonary disease with increased confusion or memory loss and functional limitations among adults in 21 states, 2011 behavioral risk factor surveillance system. Prev Chronic Dis. 2016; 13:E02.

39. Borson S, Scanlan J, Friedman S, et al. Modelling the impact of COPD on the brain. Int J Chron Obstruct Pulmon Dis. 2008;3(3):429-434.

40. Zhang H, Wang X, Lin J, et al. Reduced regional gray matter volume in patients with chronic obstructive pulmonary disease: a voxel-based morphometry study. Am J Neuroradiol. 2013;34(2):334-339.

41. Esser RW, Stoeckel MC, Kirsten A, et al. Structural brain changes in patients with chronic obstructive pulmonary disease. Chest. 2016; 149(2):426-434
42. Cleutjens F, Spruit MA, Beckervordersandforth J, et al. Presence of brain pathology in deceased subjects with and without chronic obstructive pulmonary disease. Chron Respir Dis. 2015;12(4):284-290.

43. Van Dijk EJ, Vermeer SE, de Groot JC, et al. Arterial oxygen saturation, COPD, and cerebral small vessel disease. J Neurol Neurosurg Psychiatry. 2004;75(5):733-736.

44. Shipley BA, Der G, Taylor MD, Deary IJ. Cognition and mortality from the major causes of death: the health and lifestyle survey. J Psychosom Res. 2008;65(2):143-152.

45. Antonelli-Incalzi R, Corsonello A, Pedone C, et al. Drawing impairment predicts mortality in severe COPD. Chest. 2006;130(6):1687-1694.

46. Emery CF. Exercise, chronic obstructive pulmonary disease, and cognition. In: Spirduso WW, Poon LW, Chodzko-Zajko W, editors. Exercise and Its Mediating Effect on Cognition. Champaign, IL: Human Kinetics Publishers; 2008. (googlebooks.com).

47. Kozora E, Make BJ. Cognitive improvement following rehabilitation in patients with COPD. Chest. 2000;117(5 Suppl 1):249S.

48. Emery CF, Shermer RL, Hauck ER, Hsiao ET, MacIntyre NR. Cognitive and psychological outcomes of exercise in a 1 year follow-up - study of patients with COPD. Health Psychol. 2003;22(6):598-604.

49. Incalzi RA, Corsonello A, Trojano L, et al. Cognitive training is ineffective in hypoxemic COPD: a six-month randomized controlled trial. Rejuvenation Res. 2008;11(1):239-250.

50. Carver CS, Connor-Smith J. Personality and coping. Annu Rev Psychol. 2010;61:679-704

51. Güell R, Resqueti V, Sangenis M, et al. Impact of pulmonary rehabilitation on psychosocial morbidity in patients with severe COPD. Chest. 2006;129(4):899-904.

52. Shipley BA, Weiss A, Der G, Taylor MD, Deary IJ. Neuroticism, extraversion, and mortality in the UK Health and Lifestyle Survey: a 21-year prospective cohort study. Psychosom Med. 2007;69(9):923-931.

53. Majda A, Józefowska H. Zasoby osobiste pacjentów z przewlekłą obturacyjną chorobą płuc [Personal resources of patients with COPD] Problemy Pielegniarstwa [Nursing Issues]. 2009;17:283-293. Polish.

54. Bonsaksen T, Lerdal A, Fagermoen MS. Factors associated with self-efficacy in persons with chronic illness. Scand J Psychol. 2014; 53(4):333-339.

55. Kohler CL, Fish L, Greene PG. The relationship of perceived selfefficacy to quality of life in chronic obstructive pulmonary disease. Health Psychol. 2002;21(6):610-614.

56. Khdour MR, Hawwa AF, Kidney JC, Smyth BM, McElnay JC. Potential risk factors for medication non-adherence in patients with chronic obstructive pulmonary disease (COPD). Eur J Clin Pharm. 2012;68(10): 1365-1373.

57. Yuet LM, Alexander M, Chun CJ. Coping and adjustment in Chinese patients with chronic obstructive pulmonary disease. Int J Nurs Stud. 2002;39(4):383-395.

58. Barton C, Clarke D, Sulaiman N, Abramson M. Coping as a mediator of psychosocial impediments to optimal management and control of asthma. Respir Med. 2003;97(7):747-761.

59. Albuquerque SC, Carvalho ER, Lopes RS, et al. Ego defence mechanisms in COPD: impact on health-related quality of life and dyspnoea severity. Qual Life Res. 2011;20(9):1401-1410.

60. McCathie HC, Spence SH, Tate RL. Adjustment to chronic obstructive pulmonary disease: the importance of psychological factors. Eur Respir J. 2002;19(1):47-53.

61. Janowski K, Kurpas D, Kusz J, Mroczek B, Jedynak T. Health-related behavior, profile of health locus of control and acceptance of illness in patients suffering from chronic somatic diseases. PLoS One. 2013; 8(5):e63920.

62. Penninx BWJH, Tilburg van T, Boeke AJP, Deeg DJH, Kreigsman DMW, Eijk van JThM. Effects of social support and personal coping resources on depressive symptoms: different for various chronic diseases? Health Psychol. 1998;17(6):551-558.

63. Włodarczyk D. Optimism and hope as predictors of subjective health in post-myocardial infarction patients: a comparison of the role of coping strategies. J Health Psychol. Epub 2015 Aug 31. 
64. Von Leupoldt A, Fritzhe A, Trueba AF, Meuret AE, Ritz T. Behavioral medicine approaches to chronic obstructive pulmonary disease. Ann Behav Med. 2012;44(1):52-65.

65. Kühl K, Shürmann W, Rief W. Mental disorders and quality of life in COPD patients and their spouses. Int J Chron Obstruct Pulmon Dis. 2008;3(4):727-736.

66. Cully JA, Graham DP, Stanley MA, et al. Quality of life in patients with chronic obstructive pulmonary disease and comorbid anxiety and depression. Psychosomatics. 2006;47(4):312-319.

67. Howard C, Hallas CN, Wray J, Carby M. The relationship between illness perceptions and panic in chronic obstructive pulmonary disease. Behav Res Ther. 2009;47(1):71-76.

68. Torheim H, Kvangarsnes M. How do patients with exacerbated chronic obstructive pulmonary disease experience care in the intensive care unit? Scand J Caring Sci. 2014;28(4):741-748.

69. Teixeira PJZ, Porto L, Kristensen CH, Santos AH, Menna-Barreto SS, Prado-Lima PASD. Post-traumatic stress symptoms and exacerbations in COPD patients. COPD. 2014;12(1):90-95.

70. Zbozinek TD, Rose RD, Wolitzky-Taylor KB, et al. Diagnostic overlap of generalized anxiety disorder and major depressive disorder in a primary care sample. Depress Anxiety. 2012;29(12): 1065-1071.

71. Aghanwa HS, Erhabor GE. Specific psychiatric morbidity among patients with chronic obstructive pulmonary disease in a Nigerian hospital. J Psychsom Res. 2001;50(4):179-183.

72. Engström C-P, Persson L-O, Larsson S, Ryden A, Sullivan M. Functional status and well-being in chronic obstructive pulmonary disease with regard to clinical parameters and smoking: a descriptive and comparative study. Thorax. 1996;51(8):825-830.

73. Kvaal K, Macijauskiene J, Engedal K, Laake K. High prevalence of anxiety symptoms in hospitalised geriatric patients. Int J Geriatr Psychiatry. 2001;16(7):690-693.

74. Bråtas O, Espnes GA, Rannestad T, Walstad R. Characteristics of patients with chronic obstructive disease choosing rehabilitation. $J$ Rehabil Med. 2010;42(4):362-367.

75. Tödt K, Skargren E, Jakobsson P, Theander K, Unosson M. Factors associated with low physical activity in patients with chronic obstructive pulmonary disease: a cross-sectional study. Scand J Caring Sci. 2015;29(4):697-707.

76. Kunik ME, Roundy K, Veazey C, et al. Surprisingly high prevalence of anxiety and depression in chronic breathing disorders. Chest. 2005; 127(4):1205-1211.

77. Iguchi A, Senjyu H, Hayashi $Y$, et al. Relationship between depression in patients with COPD and the percent predicted FEV1, BODE index, and health-related QOL. Respir Care. 2013;58(2):334-339.

78. Hanania NA, Müllerova H, Locantore NW, et al; Evaluation of COPD Longitudinally to Identify Predictive Surrogate Endpoints (ECLIPSE) study investigators. Determinants of depression in the ECLIPSE chronic obstructive pulmonary disease cohort. Am J Respir Crit Care Med. 2011;183(5):604-611.

79. Fuller-Thomson E, Lacombe-Duncan A. Understanding the association between chronic obstructive pulmonary disease and current anxiety: a population-based study. COPD. Epub 2016 Feb 1:1-10.

80. Baraniak A, Sheffield D. The efficacy of psychologically based interventions to improve anxiety, depression and quality of life in COPD: a systematic review and meta-analysis. Patient Educ Counc. 2011;83(1): 29-36.

International Journal of COPD

\section{Publish your work in this journal}

The International Journal of COPD is an international, peer-reviewed journal of therapeutics and pharmacology focusing on concise rapid reporting of clinical studies and reviews in COPD. Special focus is given to the pathophysiological processes underlying the disease, intervention programs, patient focused education, and self management protocols.
81. Coventry PA, Bower P, Keyworth C, et al. The effect of complex interventions on depression and anxiety in chronic obstructive pulmonary disease: systematic review and meta-analysis. PLoS One. 2013;8(4):e60532.

82. Fritzsche A, Clamor A, von Leupoldt A. Effects of medical and psychological treatment on depression in patients with COPD - a review. Respir Med. 2011;105(10):1422-1433.

83. Rose C, Wallace L, Dickson R, et al. The most effective psychologicallybased treatments to reduce anxiety and panic in patients with chronic obstructive pulmonary disease (COPD): a systematic review. Patient Educ Couns. 2002;47(4):311-318.

84. Hynninen MJ, Bjerke N, Pallesen S, Bakke PS, Nordhus IH. A randomized controlled trial of cognitive behavioral therapy for anxiety and depression in COPD. Respir Med. 2010;104(7):986-994.

85. Kunik ME, Veazey C, Cully JA, et al. COPD education and cognitive behavioural therapy group treatment for clinically significant symptoms of depression and anxiety in COPD patients a randomized controlled trial. Psychol Med. 2007;38(3):385-396.

86. Valenza MC, Valenza-Pena G, Torres-Sanchez I, Gonzalez-Jimenez E, Conde-Valero A, Valenza-Demet G. Effectiveness of controlled breathing techniques on anxiety and depression in hospitalized patients with COPD: a randomized clinical trial. Respir Care. 2014; 59(2):209-215.

87. Bratås $\mathrm{O}$. Rehabilitation in patients with chronic obstructive pulmonary disease (COPD). In: Innstrand ST, editor. Health Promotion - Theory and Practice. Trondheim: NTNU; 2012:111-124.

88. Coventry PA, Hind D. Comprehensive pulmonary rehabilitation for anxiety and depression in adults with chronic obstructive pulmonary disease: systematic review and meta-analysis. J Psychosom Res. 2007; 63(5):551-565.

89. Yohannes AM, Connolly MJ. Do antidepressants work in patients with chronic obstructive pulmonary disease with comorbid depression? Expert Rev Respir Med. 2011;5(6):727-729.

90. Bentsen SB, Rokne B, Klopstad Wahl A. Comparison of healthrelated quality of life between patients with chronic obstructive pulmonary disease and the general population. Scand J Caring Sci. 2012:27(4):905-912.

91. Blakemore A, Dickens C, Guthrie E, et al. Depression and anxiety predict health-related quality of life in chronic obstructive pulmonary disease: systematic review and meta-analysis. Int $J$ Chron Obstruct Pulmon Dis. 2014;9:501-512.

92. Yohannes AM, Willgoss TG, Fatoye FA, Dip MD, Webb K. Relationship between anxiety, depression, and quality of life in adult patients with cystic fibrosis. Respir Care. 2012;57(4):550-556.

93. Hoth K, Wamboldta FS, Bowlera R, Makea B, Holma KE. Attributions about cause of illness in chronic obstructive pulmonary disease. J Psychosom Res. 2011;70(5):465-472.

94. Torres JP, Casanova C, Hernandez C, et al. Gender associated differences in determinants of quality of life in patients with COPD: a case series study. Health Qual Life Outcomes. 2006;4:72.

95. Korczak D, Huber B, Steinhausem G, Dietl M. Outpatient pulmonary rehabilitation - rehabilitation models and shortcomings in outpatient aftercare. GMS Health Technol Assess. 2010;6:Doc11. Found in internet December 16, 2011. Available from: http://www.ncbi.nlm.nih.gov/pmc/ articles/PMC3010890/pdf/HTA-06-11.pdf.

96. Lox CL, Freehill AJ. Impact of pulmonary rehabilitation on selfefficacy, quality of life, and exercise tolerance. Rehabil Psychol. 1999;2: 208-221.

This journal is indexed on PubMed Central, MedLine and CAS. The manuscript management system is completely online and includes a very quick and fair peer-review system, which is all easy to use. Visit http://www.dovepress.com/testimonials.php to read real quotes from published authors. 